Review Article:

\title{
Prevalence and Correlates of Cigarette Smoking in Adolescent Psychiatric Inpatients in Iran: A Cross-Sectional Study and Narrative Review
}

\author{
Mehran Zarghami $^{1,2}$ (D), Arefeh Beygom Shafaat ${ }^{1,2^{*}}$ (D), Alireza Khalilian ${ }^{1,2}$, Nasrin Bali Lashak ${ }^{2}$, Mehdi Bina ${ }^{3}$, Elham Shirazi ${ }^{4}$, Mehdi Tehrani- \\ doost $^{5}$, Ebrahim Abdollahian ${ }^{6}$ (D), Mozhgan Kar Ahmadi ${ }^{7}$, Fatemeh Taghizadeh ${ }^{2}$ (iD) \\ 1. Department of Psychiatry, School of Medicine, Mazandaran University of Medical Sciences, Sari, Iran. \\ 2. Psychiatry and Behavioral Sciences Research Center, Addiction Institute, Mazandaran University of Medical Sciences, Sari, Iran. \\ 3. Department of Psychiatry, School of Medicine, Shahid Beheshti University of Medical Sciences, Tehran, Iran. \\ 4. Department of Psychiatry, School of Medicine, Iran University of Medical Sciences, Tehran, Iran. \\ 5. Department of Psychiatry, School of Medicine, Tehran University of Medical Sciences, Tehran, Iran. \\ 6. Department of Psychiatry, School of Medicine, Mashhad University of Medical Sciences, Mashhad, Iran. \\ 7. Department of Psychiatry, School of Medicine, Isfahan University of Medical Sciences, Isfahan, Iran.
}

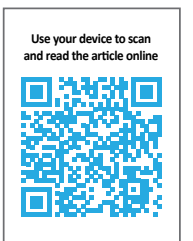

Chtration Zarghami M, Beygom Shafaat A, Khalilian A, Bali Lashak N, Bina M, Shirazi E, et al. Prevalence and Correlates of Cigarette Smoking in Adolescent Psychiatric Inpatients in Iran: A Cross-Sectional Study and Narrative Review. Journal of Pediatrics Review. 2019; 7(3):151-160. http://dx.doi.org/10.32598/jpr.7.3.151

dolihttp://dx.doi.org/10.32598/jpr.7.3.151

(c) (1) (8)

Article info:

Received: 02 July 2018

First Revision: 26 August 2018

Accepted: 01 October 2018

Published: 01 July 2019
Keywords:

Smoking, Adolescent, Inpatient

\begin{abstract}
A B S T R A C T
Context: Smoking in adolescence is a worldwide health problem. Understanding the prevalence of smoking and its clinical correlates in adolescent inpatients is useful for mental health staff to plan effective programs to reduce its detrimental consequences. In this study, we investigated the prevalence and correlates of cigarette smoking and its sociodemographic and clinical correlates. We performed a narrative review of cigarette smoking prevalence among adolescents as well as a descriptive study in inpatient adolescents in Iran.
\end{abstract}

Evidence Acquisition: This was a multicentric, cross-sectional, and hospital-based survey. In total, 82 patients (male/female: $66.9 \%$ vs. $33.1 \%$ ) were consecutively recruited from 5 child and adolescent inpatient psychiatric wards of Iran. The study data were collected from patients, their family members and patients' medical records. The descriptive statistics, Pearson's chi-squared test, and univariate logistic regression analyses were employed to analyze the obtained data. Additionally, we added a narrative review to understand the prevalence rate of smoking and its clinical correlates in adolescent inpatients.

Results: The prevalence rate of smoking was $30 \%$ in our study sample $(24.5 \%$ in boys and $39.5 \%$ in girls). There was a significant association between smoking with family size, history of suicide attempt, physical illness, drug misuse in patients, and alcohol or drug misuse in family members. The prevalence of mood disorders in the nonsmokers and smokers were $37.5 \%$ and $62.5 \%$, respectively. Overall, $26.6 \%$ of the subjects had a history of suicide attempt of whom, $52.9 \%$ were smokers.

Conclusions: Results of this study about the association between smoking with family size, history of suicide attempt, physical illness, drug misuse, and other related factors, call for both careful screening of smoking and specially designed integrated psychiatric/smoking treatments in these patients.

\section{* Corresponding Author}

Arefeh Beygom Shafaat, MD.

Address: Department of Psychiatry, School of Medicine, Mazandaran University of Medical Sciences, Sari, Iran

Tel: +98 (11) 33285109

E-mail: shafaat_arefeh@yahoo.com 


\section{Context}

moking in adolescence is a worldwide health problem, and more than $80 \%$ of smokers start smoking before the age of 18 (1). An extremely high ratio of the world's smokers is in lowor middle-income countries (2). The global death number due to smoking is estimated to be over 6 million annually, with approximately twothirds of these deaths occurring in developing countries (3). In addition to all-cause mortality, some prospective studies have revealed a significant relationship between smoking and suicide in adolescents and adults (4).

Nicotine dependence is found in only $12.8 \%$ of the USA population; although, $57.5 \%$ of all cigarettes are smoked by psychiatric patients in this country (5). The prevalence of cigarette smoking is higher among psychiatric patients than the normal population (6). In many European countries, persons with mental disorders smoke about 2 times higher than the normal population (7). A survey in Germany revealed that cigarette smokers are more vulnerable to psychiatric disorders (8). A cohort study found higher risks of suicide in adolescents who smoke cigarette (9). Psychological autopsy has revealed that previous and current smoking modifies suicide risk related to affective disorders; however, current smoking increases suicide risk associated with substance use disorders (10).

The intersection between psychiatric disorders and two complex multifactorial behaviors, cigarette smoking and suicide, have major public health effects (11). However, whether smoking represents a causal risk factor for completed suicide or only indirectly addresses those with mental disorder remains undiscovered (12, 13). Psychiatric patients account for approximately $50 \%$ of cigarette smoking in the United States (14). Cigarette smoking and less successful attempts to quit smoking is 2-4 times higher in people with substance dependence, psychosis, anxiety, and mood disorders, compared to the general population (5). Cigarette smoking in adolescence or early adulthood may be associated with later major depression, an association not related to variables such as alcohol use (15). However, not all studies have reported such association, and some suggest a reverse relationship (16).

A study suggested a slight but significant predictive relationship between depression and tobacco smoking. The same research explains a self-medication hypothesis whereby depressed patients smoke to reduce their symptoms (16). There are strong associations between anxiety and depression among young persons (14), and tobacco smoking and anxiety disorders like panic disorder (17). Depression is prevalent among adolescents, and suicide is the third cause of death among 15- to 19-year-old people. However, these associated factors have not been systematically studied in a nationally representative sample (18).

In this regard, understanding the prevalence of smoking and its clinical correlates in adolescent inpatients is useful for mental health workers to plan effective programs to reduce its detrimental consequences. The current study aimed to conduct a narrative review on cigarette smoking prevalence among adolescents in Iran. We also investigated the rate and related factors of smoking among adolescent psychiatric inpatients in Iran.

\section{Evidence Acquisition}

In a narrative review, electronic databases including, PubMed, Medline, Scopus, Google Scholar and National Persian databases of SID, IranDoc, IranPsych, IranMedex, and Magiran were utilized to find relevant articles about the prevalence of cigarette smoking in adolescents. The included studies were the quantitative estimates of cigarette use prevalence among adolescents in Iran from 2000 to 2017, using the following search keywords: "adolescents", "teen", "teenager", "youth" ,"smoking", "cigarette smoking", "tobacco smoking", and "Iran". Finally, 22 studies were included. The interested measures were the prevalence rates of current or lifetime experimental smoking in adolescents.

In a study in Tehran on 984 patients with Serious Mental Illness (SMI), 70\% of participants were smokers, $4.8 \%$ were former smokers, and $70.0 \%$ were occasional smokers (19). The prevalence rate of current smoking in 365 male adolescent students in Zarandieh City, Iran was $15.1 \%$ (20). Overall, $51 \%$ (95\%Cl: $46.5-55.7)$ of the male high school students of Shahroud (northeastern Iran) reported at least one time history of smoking, and $7.1 \%(95 \% \mathrm{Cl}: 510)$ of them were current smokers (21). In total, $14.7 \%$ of 2538 the secondary and high school students from 10 provinces in Iran reported current use of tobacco (22). In 860 high school student samples, $6.4 \%(6.1 \%$ of male students and $6.6 \%$ of female students) smoked at least once in their life. Moreover, $2.1 \%$ of the students $(1.7 \%$ of males and $2.3 \%$ of females) smoked occasionally, and $1.2 \%$ ( $2.8 \%$ of males and $0.4 \%$ of females) were current smokers (23).

In another study, $25.5 \%$ of 4523 high school students never smoked cigarettes, and $22 \%$ smoked more than 
5 cigarettes per day at the time of the study (24). Totally, $77.4 \%$ of 1785 students in Tabriz City reported that they never smoked, $18.2 \%$ had smoked cigarettes at least once, and $4.4 \%$ reported that they were current smokers (25). A systematic review estimated the prevalence of cigarette and substance use among 80588 high school students in Iran as $16.8 \%(95 \% \mathrm{Cl}$ : 16.4-17.2) (26). In another study, $7.4 \%$ of a total of 2911 students with the mean age of 13 years in middle schools in Iran were smokers (27). Other researchers have reported that $19 \%$ of 220 students aged 18-22 years reported daily cigarette smoking (28).

Of 397 high school students (200 girls and 197 boys; mean age: 15.85 and 17.28 years, respectively) $25.4 \%$ reported current cigarette use (29). In a cross-sectional study in Rasht City (north of Iran) among 1297 students (14 to 18 years old), 366 (28.2\%) subjects never smoked and 195 (15\%) were current smokers. Among current smokers, $54.6 \%$ were irregular smokers, $45.5 \%$ were daily smokers, of whom $24.8 \%$ were daily smokers of more than 1 cigarette per day (30). In another northern city of Iran (Sari), $11.5 \%$ of the 812 participants were nicotine dependent for at least 6 months. About half of the samples started smoking at the age of 13 years or younger. All of them smoked less than 10 cigarettes per day (31).

Research on 470 Iranian secondary school male students with the mean age of 13.6 years, 82 (17.5\%) students reported lifetime tobacco smoking of once or more and $29(6.2 \%)$ were current tobacco dependents (32). Furthermore, in 4786 Iranian male people in Isfahan, the smoking prevalence was $26.2 \%$, about $8.5 \%$ of respondents had previously smoked and $26.2 \%$ of them were current smokers (33). Additionally, in 1132 tenth grade students at 20 high schools in Shiraz, 19.4\% reported histories of smoking. Moreover, $80.6 \%, 16.9 \%$, and $2.5 \%$ had never smoked, had positive smoking histories, and were regular smokers, respectively (34). A population-based study reported the frequency of cigarette smoking as $11.7 \%$, in a total number of $1810 \geq 15$ years old residents of Bandar Abbas Port (35).

A cross-sectional study on 1064 male high school students in Zanjan City, Iran revealed that $7 \%$ of adolescents were regular smokers and $27 \%$ reported usage of tobacco once during their lifetime (34). A meta-analysis reported the highest and lowest prevalence of experimental smoking in Qazvin Province in 2001 (43\%) and Kerman in 2001 (8.5\% to $11 \%$ ), respectively. Also, the highest prevalence of regular smoking was reported from Gilan Province in 2004 (15\%). In addition, the lowest prevalence was reported from Kerman in 2001 (2\%) (36). This rate has been reported much higher in Kerman University students (31\% never smoked and $11 \%$ were current smokers) (37). However, the separate prevalence of lifetime, current, and daily cigarette smoking were calculated as $14.2 \%(95 \% \mathrm{Cl}: 6.6-21.7), 2.7 \%$ (95\% Cl: $0.5-5.9)$, and $1.1 \%(95 \% \mathrm{Cl}: 0.6-2.8)$, among 5934 Iranian middle school students, respectively. The combined prevalence of current tobacco use of all kinds was $15 \%$ (95\% Cl: $10.4-19.5)$ in this population (38).

Eftekhar et al. stated that the self-reported lifelong prevalence and the prevalence of current smoking are much lower in Iran compared to many other Middle East countries. However, the number of smoking cessation attempts in Iran is lower than the stated rate in other countries of the region (39). Momtazi and Rawson argued that the early onset of tobacco smoking, with a daily use rate between $4.4 \%$ and $12.8 \%$ in Iranian high school students, is an important risk factor for other substance abuse problems (40).

\subsection{Descriptive study}

A multicenter cross-sectional study was conducted on 82 patients (aged 13-18 years) admitting to 5 psychiatric hospitals in Iran during one year. Adolescents were referred from Mazandaran, Tehran, Northern Khorasan, Eastern Azerbaijan, Lorestan, Hamedan, Qom, Isfahan, Southern Khorasan, Khorasan Razavi, and Khoozestan provinces to these hospitals. After obtaining informed consent forms from their parents, data were collected from patients, their family members, and patients' medical records. In this study, "smoker adolescent" indicates an adolescent with a lifelong history of smoking at least a few puffs of tobacco cigarettes on a regular basis. Moreover, "nonsmoker" indicates a teenager who never smoked even a few puffs on a regular basis. Drug misuse demonstrates the improper use of medications.

\subsubsection{Psychiatric diagnosis}

The patients were assessed by the child and adolescent psychiatrists and diagnosis were made based on DSM V-TR criteria. Extensive information on sociodemographic factors, parental, family conditions, smoking, alcohol problems, and drug misuse was also collected.

\subsubsection{Data analysis}

The descriptive analyses, as well as the Chi-squared tests (The Pearson's chi-squared test, Fisher's exact test and Linear-by-Linear association test), were employed. 
In addition, we applied univariate logistic regression analyses to identify the study variables associated with suicidal ideation, physical illness, alcohol or drug misuse, smoking in the family, history of suicide, family size, and other related variables. There is sufficient evidence that smoking is associated with an increased risk of suicidal behaviors (41).

Current smoking is reliably associated with suicide in case-control and cohort studies (42). Variables that were associated with suicide attempts at $\mathrm{P} \leq 0.05$ were included in the multivariate logistic regression models in this study. Logistic regression analyses were used to examine the association between smoking and other variables. The data were adjusted in terms of several sociodemographic and clinical characteristics. All analyses were performed in SPSS.

\section{Results}

In total, 82 of the 101 patients accepted to participate in the project and responded to the questions about demographic variables and substance and alcohol abuse, cigarette smoking, and drug misuse. Their age range was $13-18$ years and their mean age was 15.7 years. The participants included 25 (30\%) smokers and 57 (70\%) nonsmokers (Figure 1), and 49 males and 33 females. Overall, 12 (24.5\%) boys and 13 (39.5\%) girls were smokers. The prevalence number of cigarette smokers in our study was 25 (30\%), substance abuse was $9(11 \%)$, alcohol consumption was $13(16 \%)$, and drug misuse was $6(7 \%)$ subjects. The prevalence of smoking in the family members of smokers and nonsmokers were $83 \%$ and $39 \%$, and the prevalence of drug misuse in smokers and nonsmokers were $86 \%$ and $14 \%$, respectively.
Moreover, 17 (26.6\%) patients had a history of suicide attempt, of whom 9 (52.9\%) were smokers.

In $24 \%$ of the smokers, two or more than two family members, and in $76 \%$ of them, three or more than three family members were smokers. Furthermore, 16 smokers lived with both parents, 7 smokers lived with one parent and 2 smokers lived with no parents. The same rates were 47,7 , and 3 in non-smokers. About $77 \%$ of smokers' family members were alcohol and or substance users. The frequency of psychiatric disorders, cigarette smoking, and alcohol/substance use are presented in Tables 1, 2, and 3.

Using the Chi-Squared test, the difference between alcohol consumption and drug misuse was significant $(P=0.001)$. Also, there was a significant difference between drug misuse and cigarette smoking ( $P=0.028)$ and alcohol consumption ( $P=0.029)$ in the subjects' family members. Logistic regression analyses revealed a significant association between smoking and family size $(P=0.04)$, history of suicide attempt $(P=0.01)$, physical illness $(P=0.03)$, drug misuse in patients $(P=0.02)$, and alcohol or drug misuse in their family members $(P=0.0001)$. The Chi-squared test suggests a significant difference between smoking and smoking in family members $(P=0.0001)$. There was no significant difference between smoking, drug misuse, and alcohol use in terms of gender and age ( $\mathrm{P}>0.05)$.

There was no significant difference between the misuse of drugs, substance abuse, alcohol abuse and smoking by province $(P=0.7,0.1,0.1,0.5)$. No significant difference was observed between drug misuse and physical illnesses $(P=0.6)$.

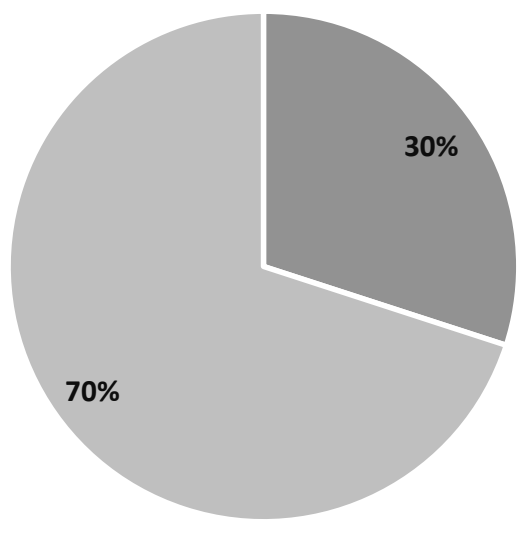

- Smoker $\quad$ Nonsmoker

Figure 1. The prevalence of cigarette smoking among adolescent psychiatric inpatients in Iran 
Logistic regression analyses demonstrated no significant difference between substance abuse and suicidal ideation, physical illness, alcohol or drug misuse, smoking in the family, history of suicide and family size $(P>0.05)$. A significant difference was detected between substance abuse and drugs misuse $(P=0.03)$, smoking $(P=0.0001)$, and living with parents $(P=0.02)$. A significant difference was observed between alcohol consumption and drug misuse, history of suicide, substance abuse, and smoking in the family $(\mathrm{P}=0.001, \mathrm{P}=0.046$, $\mathrm{P}=0.0001, \mathrm{P}=0.0001, \mathrm{P}=0.0007$, respectively). However, no significant difference was observed between alcohol consumption and suicidal ideation, family size, physical illnesses and living with parents $(P>0.05)$.

No significant difference was detected between physical illnesses and family size ( $P>0.05)$. The prevalence of mood, anxiety, and psychotic disorders, Attention/Deficit-Hyperactivity Disorder (ADHD), personality disorders, anorexia nervosa, and intellectual disability were $55 \%, 8.3 \%, 10.5 \%, 11 \%, 0.9 \%, 0.9 \%$, and $2.8 \%$, respectively.

\section{Conclusions}

In our study, the prevalence of cigarette smoking was $30 \%$. Studies report various smoking prevalence rates in deferent populations. According to a meta-analysis study in Iran, overall estimates for adolescents' cigarette smoking and chewing tobacco/pan/nas in the general population were $16.8 \%$ and $10.0 \%$, respectively (26). A national Global Youth Tobacco Survey in Nepal reported that overall, $10 \%$ of the students were ever cigarette smokers and $20.4 \%$ were tobacco users in other forms (43). In a school-based cross-sectional study conducted over a period of one year in Kashmir, India, a higher proportion of rural adolescents tried cigarette smoking (38.78\% rural vs. $20.78 \%$ urban) (10).

Another study estimated tobacco smoking prevalence among 2475 psychiatric patients attending healthcare facilities in Brazil and assessed the associated factors in a cross-sectional multicenter analysis. The current smoking prevalence rate was $52.7 \%$ (44).

Table 1. Smoking status and psychiatric diagnosis

\begin{tabular}{ccc}
\hline \multirow{2}{*}{ Psychiatric Diagnosis } & & No. (\%) \\
\cline { 2 - 3 } & Smokers & Nonsmokers \\
\hline $\begin{array}{c}\text { Mood disorder } \\
\mathrm{n}=48 \\
\text { Anxiety disorder } \\
\mathrm{n}=8\end{array}$ & $18(37.5)$ & $30(62.5)$ \\
\hline $\begin{array}{c}\text { ADHD/Disruptive behavior disorder } \\
\mathrm{n}=7\end{array}$ & $0(0)$ & $8(100)$ \\
\hline $\begin{array}{c}\text { Psychotic disorder } \\
\mathrm{n}=7\end{array}$ & $2(29)$ & $5(71)$ \\
\hline Others & $0(0)$ & $7(100)$ \\
\hline & $2(67)$ & $1(33)$ \\
\hline
\end{tabular}

Table 2. Drugs misuse, alcohol and substance abuse and suicidal ideation in smoker and nonsmoker patients

\begin{tabular}{|c|c|c|c|}
\hline & & \multicolumn{2}{|c|}{ No. (\%) } \\
\hline \multicolumn{2}{|c|}{ Variable } & \multirow{2}{*}{$\begin{array}{c}\text { Smokers } \\
5(71)\end{array}$} & \multirow{2}{*}{$\begin{array}{c}\text { Nonsmokers } \\
2(29)\end{array}$} \\
\hline & Yes & & \\
\hline & No & $17(25)$ & $52(75)$ \\
\hline \multirow{2}{*}{ Alcohol abuse } & Yes & $10(83)$ & $2(17)$ \\
\hline & No & $30(45.5)$ & $36(55)$ \\
\hline \multirow{2}{*}{ Suicidal Ideation } & Yes & $9(53)$ & $8(47)$ \\
\hline & No & $8(17)$ & $39(83)$ \\
\hline \multirow{2}{*}{ Substance abuse } & Yes & $6(75)$ & $2(25)$ \\
\hline & No & $16(23.5)$ & $52(76.5)$ \\
\hline
\end{tabular}


Table 3. Cigarette smoking by provinces

\begin{tabular}{|c|c|c|c|}
\hline \multirow{3}{*}{ Provinces } & \multicolumn{2}{|c|}{ Cigarette Smoking } & \multirow{3}{*}{$\begin{array}{c}\text { Total } \\
\text { No. (\%) }\end{array}$} \\
\hline & \multicolumn{2}{|c|}{ No. (\%) } & \\
\hline & No & Yes & \\
\hline Mazandaran & 19(79) & $5(21)$ & $24(100)$ \\
\hline Tehran & $25(66)$ & $13(34)$ & $38(100)$ \\
\hline Northern Khorasan & $1(50)$ & $1(50)$ & $2(100)$ \\
\hline Eastern Azerbaijan & $1(100)$ & $0(0)$ & $1(100)$ \\
\hline Lorestan & $0(0)$ & $1(100)$ & $1(100)$ \\
\hline Hamadan & $1(100)$ & $0(0)$ & $1(100)$ \\
\hline Qom & $1(100)$ & $0(0)$ & $1(100)$ \\
\hline Isfahan & $1(50)$ & $1(50)$ & $2(100)$ \\
\hline Southern Khorasan & $1(100)$ & $0(0)$ & $1(100)$ \\
\hline Khorasan Razavi & $6(60)$ & $4(40)$ & $10(100)$ \\
\hline Khoozestan & $1(100)$ & $0(0)$ & $1(100)$ \\
\hline Total & $57(70)$ & $25(30)$ & $82(100)$ \\
\hline
\end{tabular}

The current smoking prevalence rate in our research is lower than that study.

In a school-based study in Nepal, gender was found significantly related to the prevalence of ever tobacco users. There were higher odds of tobacco use among boys, compared with girls. The overall prevalence of 'ever users' of tobacco products was $25.3 \%$. The prevalence of tobacco users among boys and girls were $31 \%$ and $14.4 \%$, respectively. The correlates of tobacco use were gender, ethnicity, family members and friends using tobacco products; students were exposed to tobacco at home and public places (43).

Another study explored the two groups of schizophrenia and other psychiatric disorders in patients hospitalized in Kerman (Iran). In the schizophrenia group, the lowest age of smoking was 10 and the highest was 31 years. However, in the other group, the youngest age of smoking onset was 9 years and the oldest was 47 years (45). A study on adolescent psychiatric inpatients examined factors related to smoking status in this population. They concluded that $44.7 \%$ smoked 7 days a week and smokers have met the criteria for substance abuse/ dependence (46). Additionally, a cohort study followed 542 inpatients with psychosis for 10 years after the first hospitalization. In total, $52.4 \%$ of participants were current smokers and $69.3 \%$ were lifetime smokers (47), compatible with $30 \%$ lifetime smokers in our study.

Adolescents admitted to the psychiatric ward smoke more than the general adolescent populations in Iran and Nepal. Although in the general population of Kashmir, this ratio is higher than the population of Iranian adolescent psychiatric patients. However, the Iranian adolescents admitted to psychiatric wards created about half of the Caucasian patients. A large longitudinal 13-year population-based study in Norway revealed that young adult (13-27 years) smokers had clearly higher rates of anxiety, depression, and parasuicide.

After adjustment of confounding variables, nicotine dependence was still related to anxiety, depression, and parasuicide. There was also a significant association with later depression in smokers (15). The prevalence of mood disorders in our sample of nonsmokers and smokers were $37.5 \%$ and $62.5 \%$, respectively. All patients with anxiety disorder were nonsmokers in our study. About $26.6 \%$ of our patients had a history of parasuicide of whom, $52.9 \%$ were smokers. 
In another study on 950 psychiatric adult patients with serious mental illnesses who were admitted to Razi Mental Health Hospital in Tehran, Iran, $70 \%$ of samples (73.2\% males and $26.8 \%$ females) were smokers, and 219 participants had a history of suicide attempt. In the regression analysis model, gender, age, and cigarette smoking were significantly related to previous suicide attempts (19).

In our study, $73 \%$ of samples $(24.5 \%$ of males and $39.5 \%$ of females) were smokers, and $26.6 \%$ of our studied patients had previously committed suicide of whom, $52.9 \%$ were smokers. There was no significant difference between smoking and gender in our study. In a study in Korea in middle and high school students, the most highly correlated variables with suicidal attempts were smoking, depression, and inhalation experience (48). There was a significant association between smoking and suicide attempt in our study, too. In a consecutive large sample of adult patients admitting to a general hospital, suicidal ideation was related to tobacco smoking (49).

In Lineberry et al. study in adult psychiatric inpatients in Rochester (USA), 45.9\% were current smokers, and 51.1\% of them aged 18-24 years. Investigating current smoking in other psychiatric inpatient groups, substance abuse, and psychotic syndrome diagnosis were significantly correlated with current smoking (50), that is compatible with our study where a significant difference was found between smoking and substance abuse. Smoking has been identified as one of the 6 powerful independent factors in generating clinical prognostic models predicting later suicide behaviors in psychiatric patients (51).

A significant difference was observed between smoking and a history of suicide in our study, too. It has been suggested that the association between smoking and suicide attempts possibly results from depression and anxiety as well as alcohol dependency (52). In a representative sample of the USA adults, relapse, tobacco use initiation, and persistent tobacco use (which are amenable to intervention) were related to the risk of suicide attempt (53). In another study in the USA, longer lifetime smoking was associated with higher odds of suicide (54).

In another study on the USA household population, over four-fold risk for definite and or life-threatening suicide attempts was reported among smoking adolescents in inpatient psychiatric facilities compared with nonsmokers. Suicidality was more frequent among girls than boys and in adolescents suffering from depression. Suicide attempt was higher in smoker patients than nonsmokers (55). In the Dunedin Multidisciplinary Health and Development Study that is a communitybased investigation on 1037 New Zealanders born in Dunedin during 1972-1973, the authors examined the association between suicidal ideation in early adulthood and daily tobacco smoking in 764 participants. Early tobacco smoking was significantly predictive of later suicidal ideation (56).

Another study on a large population-based sample of younger people investigated the relationship between smoking and suicide mortality. Compared to youth who avoid high-risk behaviors, involvement in any drinking, smoking, and or sexual activity was related to significantly increased odds of depression, suicidal ideation, and suicide attempts (57). In our study, alcohol consumption was significantly correlated with a history of suicide, substance use, drug misuse, smoking or substance abuse in family members. In a random sample of Chilean teenagers, $25 \%$ of respondents had committed suicide at least once during life. In addition, female gender, smoking, and recent suicidal ideation were significant independent predictors of suicidal behavior (58).

Regarding the prevalent smoking behavior and its correlates in the studied patients, careful screening of smoking habits, and specially designing integrated psychiatric disorder treatments, as well as smoking cessation interventions are required. Intensified efforts are also greatly needed to prevent adolescents and young adults from starting to smoke. Furthermore, preventing adolescents from starting to smoke requires further investigating multiple background factors. The sample size was a limitation in this study and to analyze the study outcomes, a much larger sample and longer follow-up periods are needed.

\section{Ethical Considerations}

\section{Compliance with ethical guidelines}

The study was approved by Ethics Committee of Mazandaran University of Medical Sciences and executed in accordance with the Declaration of Helsinki and its subsequent revisions. Subjects were informed of the research protocol and then they provided an informed consent.

\section{Funding}

This study was supported by Mazandaran University of Medical Sciences. 


\section{Authors contributions}

Conceiving the original idea for the study, sought and obtaining the necessary fundings: Mehran Zarghami; Designing the study protocol: Fatemeh Taghizadeh, Mehran Zarghami, Arefeh Beygom Shafaat; Conducting the study and managing the day-to-day running of the research: Fatemeh Taghizadeh; Statistical analyses: Alireza Khalilian; Clinical interpretation of the results: Mehdi Bina, Elham Shirazi, Mehdi Tehranidoost; Writing the first draft of the manuscript: Fatemeh Taghizadeh; Revising the manuscript critically for important intellectual content: Mehran Zarghami, Ebrahim Abdollahian, Mozhgan Kar Ahmadi, Nasrin Bali Lashak; and Reading and approving the final version: All authors.

\section{Conflict of interest}

The authors declared no conflict of interest.

\section{References}

1. United States Public Health Service. Preventing tobacco use among youth and young adults. Washington: United States Public Health Service; 2012.

2. Jha P, Ranson MK, Nguyen SN, Yach D. Estimates of global and regional smoking prevalence in 1995 , by age and sex. American Journal of Public Health. 2002; 92(6):1002-6. [DOI:10.2105/AJPH.92.6.1002] [PMCID]

3. Wipfli H, Samet J. Global economic and health benefits of tobacco control: part 2. Clinical Pharmacology \& Therapeutics. 2009; 86(3):272-80. [DOI:10.1038/clpt.2009.94]

4. Li D, Yang X, GeZ, Hao Y, Wang Q, Liu F, et al. Cigarette smoking and risk of completed suicide: A meta-analysis of prospective cohort studies. Journal of Psychiatric Research. 2012; 46(10):1257-66. [DOI:10.1016/j.jpsychires.2012.03.013]

5. Grant BF, Hasin DS, Chou SP, Stinson FS, Dawson DA. Nicotine dependence and psychiatric disorders in the United States: Results from the national epidemiologic survey on alcohol and related conditions. Archives of General Psychiatry. 2004; 61(11):1107-15. [DOI:10.1001/archpsyc.61.11.1107]

6. Vanable PA, Carey MP, Carey KB, Maisto SA. Smoking among psychiatric outpatients: relationship to substance use, diagnosis, and illness severity. Psychology of Addictive Behaviors. 2003; 17(4):259-65. [DOI:10.1037/0893164X.17.4.259]

7. Lasser K, Boyd JW, Woolhandler S, Himmelstein DU, McCormick D, Bor DH. Smoking and mental illness: A populationbased prevalence study. JAMA. 2000; 284(20):2606-10. [DOI:10.1001/jama.284.20.2606]
8. John U, Meyer C, Rumpf HJ, Hapke U. Smoking, nicotine dependence and psychiatric comorbidity- A populationbased study including smoking cessation after three years. Drug and Alcohol Dependence. 2004; 76(3):287-95. [DOI:10.1016/j.drugalcdep.2004.06.004]

9. Riala K, Alaräisänen A, Taanila A, Hakko H, Timonen M, Räsänen P. Regular daily smoking among 14-year-old adolescents increases the subsequent risk for suicide: The Northern Finland 1966 Birth Cohort Study. The Journal of Clinical Psychiatry. 2007; 68(5):775-80. [DOI:10.4088/JCP. v68n0518]

10. Kumar V, Kumar D, Shora TN, Dewan D, Mengi V, Razaq M. Prevalence of tobacco, alcohol, and other drug abuse among school-going male adolescents in Jammu. International Journal of Medical Science and Public Health. 2016; 1(5):246-51. [DOI:10.5455/ijmsph.2016.2906201553]

11. Schneider B, Wetterling T, Georgi K, Bartusch B, Schnabel A, Blettner M. Smoking differently modifies suicide risk of affective disorders, substance use disorders, and social factors. Journal of Affective Disorders. 2009; 112(1):165-73 [DOI:10.1016/j.jad.2008.04.018]

12. Sheikh K. Re: "Cigarette smoking and suicide: a prospective study of 300,000 male active-duty army soldiers". American Journal of Epidemiology. 2000; 152(7):691-2. [DOI:10.1093/aje/152.7.691]

13. Davey Smith G, Phillips AN, Miller M, Hemenway D, Bell $\mathrm{N}$, Yore $\mathrm{M}$, et al. Re:"Cigarette smoking and suicide: A prospective study of 300000 male active-duty army soldiers". American Journal of Epidemiology. 2001; 153(3):307-8. [DOI:10.1093/aje/153.3.307]

14. McGee $R$, Feehan $M$, Williams $S$, Partridge $F$, Silva PA Kelly J. DSM-III disorders in a large sample of adolescents. Journal of the American Academy of Child \& Adolescent Psychiatry. 1990; 29(4):611-9. [DOI:10.1097/00004583199007000-00016]

15. Pedersen W, Von Soest T. Smoking, nicotine dependence and mental health among young adults: A 13-year population-based longitudinal study. Addiction. 2009; 104(1):12937. [DOI:10.1111/j.1360-0443.2008.02395.x]

16. Fergusson DM, Goodwin R, Horwood L. Major depression and cigarette smoking: Results of a 21-year longitudinal study. Psychological Medicine. 2003; 33(8):1357-67. [DOI:10.1017/S0033291703008596]

17. Breslau N, Klein DF. Smoking and panic attacks: An epidemiologic investigation. Archives of General Psychiatry. 1999; 56(12):1141-7. [DOI:10.1001/archpsyc.56.12.1141]

18. Hallfors DD, Waller MW, Ford CA, Halpern CT, Brodish PH, Iritani B. Adolescent depression and suicide risk: Association with sex and drug behavior. American Journal of Preventive Medicine. 2004; 27(3):224-31. [DOI:10.1016/ S0749-3797(04)00124-2]

19. Hooman S, Zahra H, Safa M, Hassan FM, Reza MM. Association between cigarette smoking and suicide in psychi- 
atric inpatients. Tobacco Induced Diseases. 2013; 11(1):5. [DOI:10.1186/1617-9625-11-5]

20. Karimy M, Niknami S, Heidarnia AR, Hajizadeh I, Montazeri A. Prevalence and determinants of male adolescents' smoking in Iran: An explanation based on the theory of planned behavior. Iranian Red Crescent Medical Journal. 2013; 15(3):187-93. [DOI:10.5812/ircmj.3378]

21. Chaman R, Khosravi A, Sajedinejad S, Nazemi S, Fereidoon Mohasseli K, Valizade B, et al. Smoking and its related factors among Iranian high school students. Iranian Journal of Psychiatry and Behavioral Sciences. 2015; 9(4):e1583. [DOI:10.17795/ijpbs-1583] [PMID] [PMCID]

22. Mohamadkhani S. [Prevalence of cigarette smoking, alcohol drinking and illegal drugs use among Iranian adolescents (Persian)]. Journal of Kerman University of Medical Sciences. 2011; 18(1):32-42.

23. Ziaadini SH, Kheradmand A, Nakhaei N, Taherzadeh $\mathrm{H}$. [Prevalence of cigarette smoking and relevant factors among school students in south of Iran (Persian)]. Journal of Fundamentals of Mental Health. 2008; 10(3):239-45.

24. Ramezankhani A, Sarbandizaboli F, Zarghi A, Heidari G, Masjedi M. [Pattern of cigarette smoking in adolescent students in Tehran (Persian)]. Pajoohandeh Journal. 2010; 15(3):115-22.

25. Mohammadpoor Asl A, Fakhari A, Rostami F, Pourafkary N. Cigarette smoking among Iranian adolescents. Iranian Journal of Psychiatry and Behavioral Sciences. 2007; 1(1):30-5.

26. Ansari Moghaddam A, Rakhshani F, Shahraki Sanavi F, Mohammadi M, Miri Bonjar M, Bakhshani NM. Prevalence and patterns of tobacco, alcohol, and drug use among Iranian adolescents: A meta-analysis of 58 studies. Children and Youth Services Review. 2016; 60:68-79. [DOI:10.1016/j. childyouth.2015.11.018]

27. Hadi MAE, Jalilvand M, Hadian M, Heydari G. Efficacy of different methods in decreasing the students' tendency towards smoking. Tanaffos. 2008; 7(3):53-8.

28. Jodati A, Shakurie S, Nazari M, Raufie M. Students attitudes and practices towards drug and alcohol use at Tabriz University of Medical Sciences. Eastern Mediterranean Health Journal. 2007; 13(4):962-7.

29. Ahmadi J, Hasani M. Prevalence of substance use among Iranian high school students. Addictive Behaviors. 2003; 28(2):375-9. [DOI:10.1016/S0306-4603(01)00246-5]

30. Mohtasham Amiri Z, Cirus Bakht S, NikRavesh Rad SR. [Cigarette smoking among male high school students in Rasht (Persian)]. Journal of Guilan University of Medical Sciences. 2008; 17(65):100-7.

31. Zarghami M, Khalilian AR, Veriani AR. [Cigarette smoking among sari highschool students (Persian)]. Iranian Red Crescent Medical Journal. 2003; 6(1):40-6.
32. Ahmadi J, Alishahi M, Alavi M. Substance use disorders in a sample of Iranian secondary school students. Social Indicators Research. 2004; 65(3):355-60. [DOI:10.1023/ B:SOCl.0000003547.60431.d0]

33. Rajabizadeh $G$, Ramezani MA, Roohafza $H$, Pourdamghan $\mathrm{N}$, Khosravi A, Rabiei K, et al. Association between cigarette smoking and socio-demographics, lifestyle and mental health factors in a sampled Iranian population. Southeast Asian Journal of Tropical Medicine and Public Health. 2011; 42(4):977-87. [PMID]

34. Ayatollahi SA, Rajaeifard A, Mohammadpoorasl A. Predicting the stages of smoking acquisition in the male students of Shiraz's high schools, 2003. Nicotine \& Tobacco Research. 2005; 7(6):845-51. [DOI:10.1080/14622200500330233] [PMID]

35. Agha Molaei T, Zare Sh. [Cigarette and hookah using pattern in over-15 population of Bandar Abbas, a population based study (Persian)]. Hormozgan Medical Journal. 2008; 11(4):241-6.

36. Nazarzadeh M, Bidel Z, Ayubi E, Bahrami A, Jafari F, Mohammadpoorasl A, et al. [Smoking status in Iranian male adolescents: A cross-sectional study and a meta-analysis (Persian)]. Addictive Behaviors. 2013; 38(6):2214-8. [DOI:10.1016/j.addbeh.2013.01.018] [PMID]

37. Shamsi Meymandi M, Nakhaee N, Divsalar K, Heravi G. [Cigarette smoking among Iranian university students: Reasons and attitudes (Persian)]. Iranian Journal of Psychiatry and Behavioral Sciences. 2010; 4(2):37-41.

38. Hefazi M, Sahimi-Izadian E, Rahimi-Movaghar A, AminEsmaeili M, Razaghi EM, Yousefi-Nooraie R. The prevalence of smoking among Iranian middle school students, a systematic review. Iranian Journal of Psychiatry. 2007; 2(4):157-64.

39. Eftekhar Ardebili M, Nassr M, Rassulian M, Ghalebandi MF, Daneshamuz B, Salehi M. Prevalence of cigarette smoking in Tehran: A household study. Iranian Journal of Psychiatry and Behavioral Sciences. 2007; 1(2):33-7.

40. Momtazi S, Rawson RA. Substance abuse among Iranian high school students. Current Opinion in Psychiatry. 2010; 23(3):221-6. [DOI:10.1097/YCO.0b013e328338630d] [PMID]

41. Poorolajal J, Darvishi N. Smoking and suicide: A meta-analysis. PLOS One. 2016; 11(7):e0156348. [DOI:10.1371/journal.pone.0156348] [PMID]

42. Hughes JR. Smoking and suicide: A brief overview. Drug and Alcohol Dependence. 2008; 98(3):169-78. [DOI:10.1016/j. drugalcdep.2008.06.003] [PMID]

43. Bhaskar RK, Sah MN, Gaurav K, Bhaskar SC, Singh R, Yadav $\mathrm{MK}$, et al. Prevalence and correlates of tobacco use among adolescents in the schools of Kalaiya, Nepal: A cross-sectional questionnaire based study. Tobacco Induced Diseases. 2016; 14:11. [DOI:10.1186/s12971-016-0075-x] [PMID]

44. Barros FCRd, Melo APS, Cournos F, Cherchiglia ML, Peixoto ERdM, Guimarães MDC. Cigarette smoking among psychi- 
atric patients in Brazil. Cadernos de Saúde Pública. 2014; 30(6):1195-206. [DOI:10.1590/0102-311X00027113] [PMID]

45. Ziaaddini $H$, Kheradmand A, Vahabi M. Prevalence of cigarette smoking in schizophrenic patients compared to other hospital admitted psychiatric patients. Addiction and Health. 2010; 1(1):38-42.

46. Ramsey SE, Brown RA, Strong DR, Sales SD. Cigarette smoking among adolescent psychiatric inpatients: Prevalence and correlates. Annals of Clinical Psychiatry. 2002; 14(3):149-53. [DOI:10.3109/10401230209147451] [PMID]

47. Kotov R, Guey LT, Bromet EJ, Schwartz JE. Smoking in schizophrenia: Diagnostic specificity, symptom correlates, and illness severity. Schizophrenia Bulletin. 2010; 36(1):173-81. [DOI:10.1093/schbul/sbn066] [PMID]

48. Hooman S, Zahra H, Safa M, Hassan FM, Reza MM. Association between cigarette smoking and suicide in psychiatric inpatients. Tobacco Induced Diseases. 2013; 11:5. [DOI:10.1186/1617-9625-11-5]

49. Yi S, Yi Y, Jung HS. Factors on the suicidal attempt by gender of middle and high school student. Journal of Korean Academy of Nursing. 2011; 41(5):652-62. [DOI:10.4040/ jkan.2011.41.5.652] [PMID]

50. Botega NJ, de Azevedo RCS, Mauro MLF, Mitsuushi GN, Fanger PC, Lima DD, et al. Factors associated with suicide ideation among medically and surgically hospitalized patients. General Hospital Psychiatry. 2010; 32(4):396-400. [DOI:10.1016/j.genhosppsych.2010.02.004] [PMID]

51. Lineberry TW, Allen JD, Nash J, Galardy CW. Populationbased prevalence of smoking in psychiatric inpatients: A focus on acute suicide risk and major diagnostic groups. Comprehensive Psychiatry. 2009; 50(6):526-32. [DOI:10.1016/j. comppsych.2009.01.004] [PMID]

52. Galfalvy HC, Oquendo MA, Mann JJ. Evaluation of clinical prognostic models for suicide attempts after a major depressive episode. Acta Psychiatrica Scandinavica. 2008; 117(4):24452. [DOI:10.1111/j.1600-0447.2008.01162.x] [PMID]

53. Cherpitel CJ, Borges GL, Wilcox HC. Acute alcohol use and suicidal behavior: A review of the literature. Alcoholism: Clinical and Experimental Research. 2004; 28(s1):18S-28. [DOI:10.1097/01.ALC.0000127411.61634.14] [PMID]

54. Berlin I, Hakes JK, Hu MC, Covey LS. Tobacco use and suicide attempt: Longitudinal analysis with retrospective reports. PLOS One. 2015; 10(4):e0122607. [DOI:10.1371/ journal.pone.0122607] [PMID]

55. Balbuena L, Tempier R. Independent association of chronic smoking and abstinence with suicide. Psychiatric Services. 2015; 66(2):186-92. [DOI:10.1176/appi.ps.201300509]

56. Mäkikyrö TH, Hakko HH, Timonen MJ, Lappalainen JA, IIomäki RS, Marttunen MJ, et al. Smoking and suicidality among adolescent psychiatric patients. Journal of Adolescent Health. 2004; 34(3):250-3. [DOI:10.1016/j.jadohealth.2003.06.008]
57. McGee R, Williams S, Nada Raja S. Is cigarette smoking associated with suicidal ideation among young people? American Journal of Psychiatry. 2005; 162(3):619-20. [DOI:10.1176/appi.ajp.162.3.619] [PMID]

58. Chen VcH, Kuo CJ, Wang TN, Lee WC, Chen WJ, Ferri CP, et al. Suicide and other-cause mortality after early exposure to smoking and second hand smoking: A 12-year populationbased follow-up study. PLOS One. 2015; 10(7):e0130044. [DOI:10.1371/journal.pone.0130044] [PMID]

59. Valdivia M, Silva D, Sanhueza F, Cova F, Melipillan R. [Suicide attempts among Chilean adolescents (Spanish)]. Revista medica de Chile. 2015; 143(3):320-8. [DOI:10.4067/S003498872015000300006] [PMID] 